http://jmscr.igmpublication.org/home/ ISSN (e)-2347-176x ISSN (p) 2455-0450

crossref DOI: https://dx.doi.org/10.18535/jmscr/v8i2.84

\title{
Myocardial Dysfunction in Critically Ill Elderly Patients Admitted with Non- Cardiac Diagnosis
}

\author{
Authors \\ Dr Yeshavanth. G', Dr Y. Dharanidhar Reddy ${ }^{2 *}$
}

${ }^{1}$ Associate Professor, S.S. Institute of Medical Sciences and Research Centre, Davangere, Karnataka, India

${ }^{2}$ Post Graduate, S.S. Institute of Medical Sciences and Research Centre, Davangere, Karnataka, India

*Corresponding Author

Dr Y. Dharanidhar Reddy

Post Graduate, S.S. Institute of Medical Sciences and Research Centre, Davangere, Karnataka, India

\begin{abstract}
Background and Objectives: In patients admitted to the Intensive Care Unit (ICU) for non cardiac disease, the diagnosis of acute coronary syndromes can be challenging. The aim of the study was to study the clinical profile of patients developing myocardial injury in critically ill elderly patients admitted to ICU for non-cardiac diagnosis and clinical profile with outcome at discharge from ICU. .

Materials and Methods: The retrospective study subjects are 130 patients admitted to medical ICU. A detailed history, a 12 lead ECG, Cardiac troponin T,CK-MB will be done within 24 hours of admission to ICU and as required based on ECG findings and development of clinical symptoms.

Results: The study revealed that 35 out of 130 patients developed acute myocardial injury. 13 out of 35 patients who had myocardial injury had fatal outcome. The prevalence of diabetes mellitus, hypertension, past history of IHD, past history of CVA and COPD reached statistical significance $(p<0.001)$ between the two groups of patients who developed myocardial injury and who did not develop myocardial injury. In patients with multiple comorbidities, the presence of following trigger factors increases the risk of mortality. These trigger factors are 1) hypotension with use of vasopressor agents 2) anemia 3) hypoxia and 4) hypoglycemia or hyperglycemia, 5)poorly supplemented hypothyroidism.

Conclusion: All elderly patients with or without multiple comorbidities who are hospitalised with acute form of stressors must be aggressively evaluated for precipitants and adequately treated to prevent myocardial injury.
\end{abstract}

\section{Introduction}

Critically ill elderly patients are at high risk for myocardial ischemia because of older age, increased intrinsic and extrinsic sympathetic stimulation, hypoxia, vasopressor use, and coagulation disorders ${ }^{1}$. In clinical practice, the diagnosis of myocardial injury in ICU patients is complicated by frequent absence of clinical symptoms and presence of confounding co morbidities. So Myocardial infarction (MI) in the critically ill patients is a diagnostic challenge and is associated with adverse outcome for the patient ${ }^{2}$. The presence of elevated cTn, in addition to ECG changes, may help to make a decision to rule in or out Myocardial injury ${ }^{3}$. So the aim of this study is to study the clinical profile of patients 
developing myocardial injury assessed by raised cardiac troponin T, ECG findings in critically ill elderly patients admitted to ICU for non-cardiac diagnosis. In other studies, patients admitted to the ICU for non-cardiac reasons, the identification of those at risk for AMI was mainly due to the concomitant conditions that can prevent an appropriate screening. In their study, the diagnostic discrepancy was higher in septic patients, in whom the correct diagnosis of AMI was established at a rate lower than $50 \%$ of cases as compared with non-septic patients ${ }^{4}$.

\section{Aims and Objectives}

1) To study myocardial injury in critically ill elderly patients admitted to ICU with noncardiac diagnosis.

2) To identify the precipitants for myocardial injury in critically ill elderly ICU patients

3) To study their clinical profile and outcome at discharge from ICU.

\section{Methodology}

A prospective study of 130 Elderly patients admitted with non-cardiac diagnosis to medical ICUs.

\section{Method of Collection of Data}

1) A detailed clinical history, basic investigations, a 12 lead ECG will be done on admission to ICU.
2) Cardiac troponin T, CK-MB will be done within 24 hours of admission to ICU and as required based on ECG findings and development of clinical symptoms.

3) Patient will be on continuous ECG monitoring of lead II and a repeat 12 lead ECG will be performed on fresh STsegment changes and clinical symptoms of cardiac injury after admission.

\section{Inclusion Criteria}

1) Patients admitted to ICU with critical noncardiac illness

2) Age more than 60 years

\section{Exclusion Criteria}

1) Patients presenting with primary cardiac diagnosis at admission.

2) Patients with post cardiac surgery, admitted with thoracic trauma with high likelihood of myocardial injury, coexisting renal failure.

\section{Investigations}

1. ECG

2. ABG analysis

3. Troponin $\mathrm{T}$

4. CK-MB

5. Serum Sodium

6. Serum Potassium

\section{Results}

Table 1: Age distribution of patients studied

Age Distribution - Mean \pm SD: $73.68 \pm 7.4$

\begin{tabular}{|lcc|}
\hline Age in years & $\begin{array}{c}\text { No. of } \\
\text { patients }\end{array}$ & $\%$ \\
\hline $61-70$ & 63 & 48.5 \\
\hline $71-80$ & 45 & 34.6 \\
\hline $81-90$ & 18 & 13.6 \\
\hline $91-100$ & 4 & 3.1 \\
\hline Total & 130 & 100.0 \\
\hline
\end{tabular}

Table 2: Gender distribution of patients studied

\begin{tabular}{|l|c|c|}
\hline Gender & No. of patients & \% \\
\hline Female & 50 & 38.5 \\
\hline Male & 80 & 61.5 \\
\hline Total & 130 & 100.0 \\
\hline
\end{tabular}


Table 3: Incidence of co-morbidities in patients studied

\begin{tabular}{|l|c|c|}
\hline & $\begin{array}{c}\text { No. of patients } \\
(\mathbf{n = 1 3 0})\end{array}$ & $\mathbf{\%}$ \\
\hline T2DM & 75 & 57.7 \\
\hline HTN & 77 & 59.2 \\
\hline T2DM+HTN & 50 & 38.4 \\
\hline OLD CVA & 33 & 25.4 \\
\hline COPD & 17 & 13.1 \\
\hline Asthma & 23 & 17.7 \\
\hline Dyslipidemia & 40 & 30.8 \\
\hline Hypothyroidism & 19 & 14.6 \\
\hline Alcohol & 27 & 20.8 \\
\hline Smoking & 29 & 22.3 \\
\hline
\end{tabular}

Table 4: Past history of IHD and management in patients studied

\begin{tabular}{|l|c|c|}
\hline OLD IHD and management & $\begin{array}{c}\text { No. of patients } \\
(\mathbf{n}=\mathbf{1 3 0})\end{array}$ & $\%$ \\
\hline Nil & 81 & 62.3 \\
\hline Yes & 49 & 37.7 \\
\hline Medicalmanagement & 23 & 17.7 \\
\hline PTCA & 16 & 12.3 \\
\hline CABG & 10 & 7.7 \\
\hline
\end{tabular}

Table 5: ICU diagnosis of patients studied

\begin{tabular}{|l|c|c|}
\hline Diagnosis & No. of patients & \% \\
\hline Pneumonia & 52 & 40.8 \\
\hline Acute gastroenteritis & 18 & 13.8 \\
\hline DCLD & 14 & 10.8 \\
\hline Cellulitis & 12 & 9.2 \\
\hline CVA & 11 & 8.5 \\
\hline Cancer & 5 & 3.8 \\
\hline Urospesis & 11 & 8.5 \\
\hline Hypoglycemia & 7 & 5.4 \\
\hline Total & 130 & 100.0 \\
\hline
\end{tabular}

Table 6 New symptoms during ICU stay in patients studied

\begin{tabular}{|l|c|c|}
\hline mptoms during ICU stay & $\begin{array}{c}\text { No. of } \\
\text { patients (n=130) }\end{array}$ & \% \\
\hline Nil & 70 & 53.8 \\
\hline Yes & 60 & 46.2 \\
\hline Dyspnea & 28 & 46.7 \\
\hline Fatigue & 12 & 20.0 \\
\hline Atypical chestpain & 10 & 16.7 \\
\hline Alteredsensorium & 15 & 25.0 \\
\hline Epigastric pain and vomiting & 10 & 16.7 \\
\hline
\end{tabular}

Table 7: Fresh ECG changes during ICU stay in patients at the onset of symptoms

\begin{tabular}{|l|c|c|c|}
\hline \multirow{2}{*}{$\begin{array}{l}\text { Fresh ST Segment } \\
\text { changes }\end{array}$} & \multicolumn{2}{|c|}{ Symptoms } & \multirow{2}{*}{ Total } \\
\cline { 2 - 3 } & No & Yes & $95(73.1 \%)$ \\
\hline Nil & $69(98.6 \%)$ & $26(43.3 \%)$ & $35(26.9 \%)$ \\
\hline Yes & $1(1.4 \%)$ & $34(56.7 \%)$ & $130(100 \%)$ \\
\hline Total & $70(100 \%)$ & $60(100 \%)$ & 1 \\
\hline
\end{tabular}


Table 8: CKMB and TROP T during ICU stay in patients at the onset of symptoms

\begin{tabular}{|l|c|c|c|}
\hline \multirow{2}{*}{$\begin{array}{c}\text { CKMB \& TROP } \\
\text { Ton follow-up }\end{array}$} & \multicolumn{2}{|c|}{ Symptoms } & \multirow{2}{*}{ Total } \\
\cline { 2 - 3 } & No & Yes & $104(80 \%)$ \\
\hline Negative & $69(98.6 \%)$ & $35(58.3 \%)$ & $26(20 \%)$ \\
\hline Positive & $1(1.4 \%)$ & $25(41.7 \%)$ & $26 \%)$ \\
\hline Total & $70(100 \%)$ & $60(100 \%)$ & $130(100 \%)$ \\
\hline
\end{tabular}

Table 9: Type of Myocardial injury in relation to symptoms

\begin{tabular}{|l|c|c|c|}
\hline \multirow{2}{*}{$\begin{array}{l}\text { Type of Myocardial } \\
\text { injury }\end{array}$} & \multicolumn{2}{|c|}{ Symptoms } & \multirow{2}{*}{ Total } \\
\cline { 2 - 3 } & No & Yes & Nil \\
\hline NSTEMI & $69(98.6 \%)$ & $26(43.3 \%)$ & $95(73.1 \%)$ \\
\hline STEMI & $0(0 \%)$ & $15(25 \%)$ & $15(11.5 \%)$ \\
\hline Unstable Angina & $1(1.4 \%)$ & $10(16.7 \%)$ & $11(8.5 \%)$ \\
\hline Total & $0(0 \%)$ & $9(15 \%)$ & $9(6.9 \%)$ \\
\hline
\end{tabular}

Table 10: Association of Clinical variables in relation to Myocardial Injury

\begin{tabular}{|l|c|c|c|c|}
\hline \multirow{2}{*}{ Variables } & \multicolumn{2}{|c|}{ Myocardial Injury } & \multirow{2}{*}{ Total (n=130) } & \multirow{2}{*}{ P value } \\
\cline { 2 - 3 } & Yes (n=35) & No (n=95) & & 0.560 \\
\hline Age in years & $74.31 \pm 8.95$ & $73.45 \pm 6.84$ & $73.68 \pm 7.44$ & 0.317 \\
\hline Male & $24(68.6 \%)$ & $56(58.9 \%)$ & $80(61.5 \%)$ & 0.317 \\
\hline Female & $11(31.4 \%)$ & $39(41.1 \%)$ & $50(38.5 \%)$ & $0.001^{* *}$ \\
\hline T2DM & $34(97.1 \%)$ & $41(43.2 \%)$ & $75(57.7 \%)$ & $<0.001^{* *}$ \\
\hline HTN & $33(94.3 \%)$ & $44(46.3 \%)$ & $77(59.2 \%)$ & $<0.00$ \\
\hline Old IHD & $29(82.9 \%)$ & $20(21.1 \%)$ & $49(37.7 \%)$ & $<0.001^{* *}$ \\
\hline Old CVA & $21(60 \%)$ & $12(12.6 \%)$ & $33(25.4 \%)$ & $<0.001^{* *}$ \\
\hline Alcohol & $13(37.1 \%)$ & $14(14.7 \%)$ & $27(20.8 \%)$ & $0.005^{* *}$ \\
\hline Smoking & $17(48.6 \%)$ & $12(12.6 \%)$ & $29(22.3 \%)$ & $<0.001^{* *}$ \\
\hline COPD & $12(34.3 \%)$ & $5(5.3 \%)$ & $17(13.1 \%)$ & $<0.001^{* *}$ \\
\hline Asthma & $3(8.6 \%)$ & $20(21.1 \%)$ & $23(17.7 \%)$ & $0.098+$ \\
\hline Dyslipidemia & $19(54.3 \%)$ & $21(22.1 \%)$ & $40(30.8 \%)$ & $<0.001^{* *}$ \\
\hline Hypothyroidism & $9(25.7 \%)$ & $10(10.5 \%)$ & $19(14.6 \%)$ & $0.030^{*}$ \\
\hline Hypotension & $24(68.5 \%)$ & $40(42 \%)$ & $64(49.2 \%)$ & 0.040 \\
\hline Anemia & & & & \\
\hline Nil & $9(25.7 \%)$ & $67(70.5 \%)$ & $76(58.5 \%)$ & 0.125 \\
\hline Mild(11-12g/dl) & $3(8.6 \%)$ & $19(20 \%)$ & $22(16.9 \%)$ & 0.094 \\
\hline Moderate(8-10.9g/dl) & $15(42.9 \%)$ & $7(7.4 \%)$ & $22(16.9 \%)$ & $<0.001^{* *}$ \\
\hline Severe(<8g/dl) & $8(22.9 \%)$ & $2(2.1 \%)$ & $10(7.7 \%)$ & $<0.001^{* *}$ \\
\hline HbA1c \% & $8.85 \pm 2.30$ & $7.41 \pm 0.64$ & $8.05 \pm 1.75$ & $<0.001^{* *}$ \\
\hline PO2 (mmHg) & $52 \pm 21$ & $76 \pm 14$ & $66 \pm 16$ & $0.004^{* *}$ \\
\hline S. sodium $(\mathrm{mEq} / \mathrm{dl})$ & $128 \pm 3$ & $131 \pm 5$ & $129 \pm 6$ & 0.218 \\
\hline S. potassium(mEq/dl) & $3.6 \pm 1.1$ & $4.0 \pm 0.8$ & $3.8 \pm 0.9$ & 0.318 \\
\hline
\end{tabular}

Table 11: Past history of IHD in relation to Myocardial Injury

\begin{tabular}{|l|c|c|c|}
\hline \multirow{2}{*}{ Old IHD management } & \multicolumn{2}{|c|}{ Myocardial Injury } & \multirow{2}{*}{ Total (n=130) } \\
\cline { 2 - 3 } & Yes (n=35) & No (n=95) & Nil \\
\hline Yes & $6(17.1 \%)$ & $75(78.9 \%)$ & $81(62.3 \%)$ \\
\hline Medicalmanagement & $29(82.9 \%)$ & $20(21.1 \%)$ & $49(37.7 \%)$ \\
\hline PTCA & $7(20 \%)$ & $16(16.8 \%)$ & $23(17.7 \%)$ \\
\hline CABG & $14(40 \%)$ & $2(2.1 \%)$ & $16(12.3 \%)$ \\
\hline
\end{tabular}


Figure 1: Association of comorbidities with myocardial injury

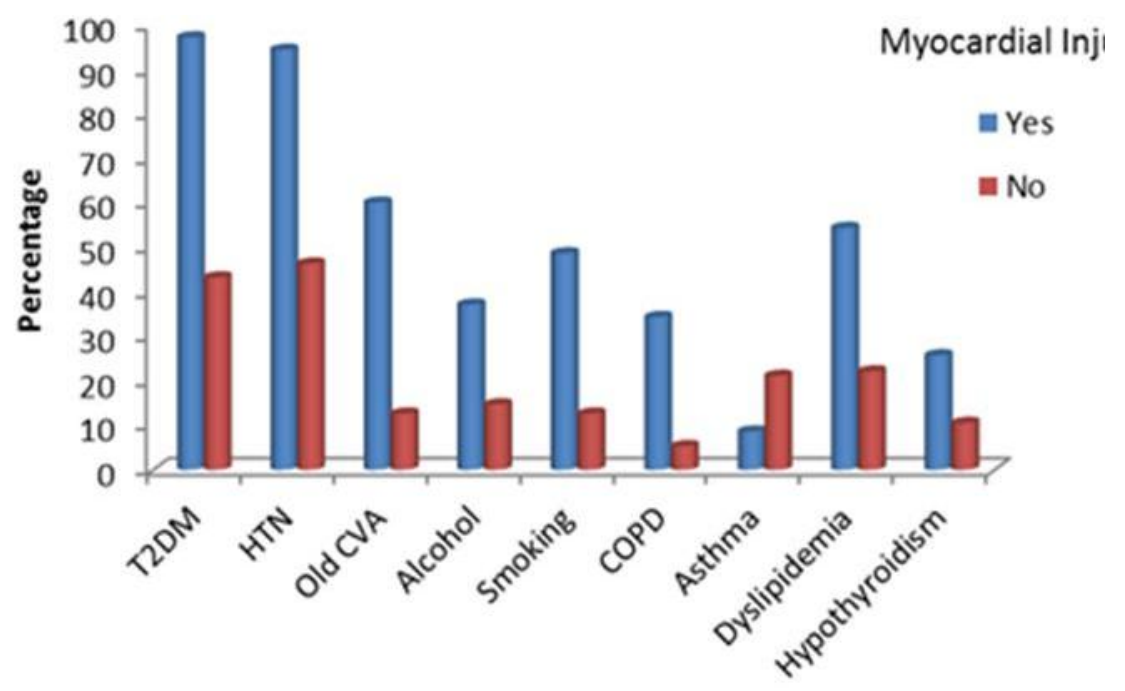

Figure 2: Association of use of inotropes with myocardial injury

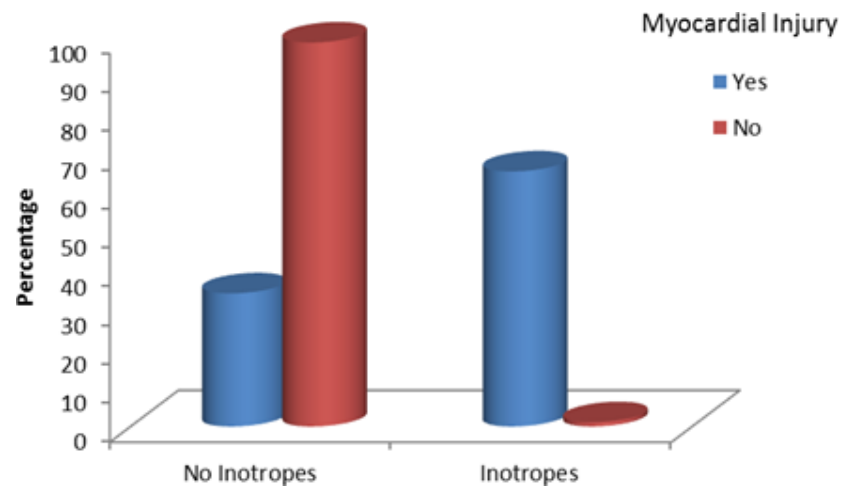

Table 12: Association of non-cardiac diagnosis with myocardial injury

\begin{tabular}{|l|c|c|c|c|}
\hline Diagnosis & $\begin{array}{c}\text { Patients with } \\
\text { myocardial } \\
\text { injury(n=35) }\end{array}$ & $\begin{array}{c}\text { Patients without } \\
\text { myocardial } \\
\text { injury(n=95) }\end{array}$ & Total(n=130) & $\begin{array}{c}\text { P } \\
\text { value }\end{array}$ \\
\hline Pneumonia & $15(42.8 \%)$ & $37(38.9 \%)$ & $52(40 \%)$ & 0.916 \\
\hline Acute gastroenteritis & $7(20 \%)$ & $11(11.5 \%)$ & $18(13.8 \%)$ & 0.217 \\
\hline DCLD & $6(17.1 \%)$ & $8(8.4 \%)$ & $14(10.7 \%)$ & 0.08 \\
\hline Cellulitis & $2(5.7 \%)$ & $10(10.5 \%)$ & $12(9.2 \%)$ & 0.760 \\
\hline Hypoglycemia & $2(5.7 \%)$ & $5(5.2 \%)$ & $7(5.3 \%)$ & 0.90 \\
\hline Cancer & $1(2.8 \%)$ & $4(4.2 \%)$ & $5(3.2 \%)$ & 0.817 \\
\hline CVA & $1(2.8 \%)$ & $10(10.5 \%)$ & $11(8.4 \%)$ & 0.716 \\
\hline Urosepsis & $1(2.8 \%)$ & $10(10.5 \%)$ & $11(8.4 \%)$ & 0.851 \\
\hline
\end{tabular}

Table 13: Association of clinical variables in relation to outcome in patients with myocardial injury

\begin{tabular}{|c|c|c|c|}
\hline \multirow[b]{2}{*}{ Variables } & \multicolumn{2}{|c|}{ Myocardial Injury } & \multirow[b]{2}{*}{ P value } \\
\hline & $\begin{array}{l}\text { Death } \\
(n=13)\end{array}$ & $\begin{array}{c}\text { Survived } \\
(\mathbf{n}=\mathbf{2 2})\end{array}$ & \\
\hline Age in years & $70.31 \pm 4.95$ & $68.45 \pm 6.84$ & 0.560 \\
\hline Male & $8(61.5 \%)$ & $16(72.7 \%)$ & 0.417 \\
\hline Female & $5(38.4 \%)$ & $6(27.2 \%)$ & 0.517 \\
\hline T2DM & $13(100 \%)$ & $21(95.4 \%)$ & 0.42 \\
\hline HTN & $13(100 \%)$ & $20(90.9 \%)$ & 0.38 \\
\hline Old IHD & $13(100 \%)$ & $16(72.7 \%)$ & $0.03 *$ \\
\hline Old CVA & $11(84.6 \%)$ & $10(45.4 \%)$ & $<0.001 * *$ \\
\hline Alcohol & $4(30.8 \%)$ & $9(40.9 \%)$ & 0.521 \\
\hline Smoking & $7(53.8 \%)$ & $10(45.4 \%)$ & 0.480 \\
\hline COPD & $5(38.4 \%)$ & $7(31.8 \%)$ & 0.612 \\
\hline
\end{tabular}




\begin{tabular}{|l|c|c|c|}
\hline Asthma & $3(23.0 \%)$ & $0 \%$ & $0.040^{*}$ \\
\hline Dyslipidemia & $9(69.2 \%)$ & $10(45.4 \%)$ & $0.021^{*}$ \\
\hline Hypothyroidism & $4(30.8 \%)$ & $5(22.7 \%)$ & 0.061 \\
\hline Hypotension & $13(100 \%)$ & $17(77.2 \%)$ & $0.021^{*}$ \\
\hline Anemia & & & \\
\hline Nil & $1(7 \%)$ & $8(36.3 \%)$ & 0.125 \\
\hline Mild(11-12g/dl) & $0 \%$ & $3(13.6 \%)$ & 0.941 \\
\hline Moderate(8-10.9g/dl) & $6(46.1 \%)$ & $9(40.9 \%)$ & 0.681 \\
\hline Severe(<8g/dl) & $6(46.1 \%)$ & $2(9 \%)$ & $<0.001^{* *}$ \\
\hline HbA1c \% & $8.95 \pm 2.30$ & $7.21 \pm 0.64$ & $<0.001^{* *}$ \\
\hline PO2 $(\mathrm{mmHg})$ & $46 \pm 26$ & $66 \pm 16$ & $0.004^{* *}$ \\
\hline S. sodium $(\mathrm{mEq} / \mathrm{dl})$ & $128 \pm 4$ & $132 \pm 3$ & 0.218 \\
\hline S. potassium(mEq/dl) & $3.6 \pm 0.8$ & $3.8 \pm 1.1$ & 0.318 \\
\hline
\end{tabular}

Table 14: I CU diagnosis in patients who expired

\begin{tabular}{|l|c|c|}
\hline Diagnosis & No. of patients & \% \\
\hline pneumonia & 6 & 46.2 \\
\hline Acute gastroenteritis & 4 & 30.8 \\
\hline Bronchogenic carcinoma & 1 & 7.7 \\
\hline DCLD & 1 & 7.7 \\
\hline Hypoglycemia & 1 & 7.7 \\
\hline Total & 13 & 100.0 \\
\hline
\end{tabular}

\section{Discussion}

Typical signs and symptoms can be difficult to elicit and surrogate physiological markers of impaired coronary perfusion are masked or misinterpreted in the context of the index pathology ${ }^{2}$. So Myocardial infarction (MI) in the critically ill patients is a diagnostic challenge and is associated with adverse outcome for the patient3.. In our study the incidence of myocardial injury in patients admitted with non-cardiac diagnosis was $26.9 \%$. Lim et al, found that $25.8 \%$ of elderly patients admitted to ICU had myocardial injury ${ }^{5}$.Atypical presentations such as acute confusion, atypical chest pain, vomiting, shortness of breath can be a manifestation of myocardial injury in critically ill elderly patients. In the present study, among many symptoms that occurred, dyspnea $(46.7 \%)$ appeared to be most common symptom, followed by altered sensorium $(25 \%)$ and fatigue(20\%). Venkatesh, et al.- also showed atypical symptoms like breathlessness, epigastric pain and burning sensation, fatigue are common presenting complaints in patients diagnosed with AMI in elderly ${ }^{6}$. The most common ICU diagnosis in patients who developed myocardial injury was pneumonia (42\%). Our results are correlating with a study done by ostermann et al; where the most common non-cardiac diagnosis was sepsis secondary to pneumonia $(40 \%)^{7}$. In the present study there was statistically significant relationship between the presence of following comorbidties and patients who had myocardial injury $(\mathrm{p}<0.001 *) \quad 1$. Diabetes $(97 \%) 2$. Hypertension (94\%)3. Past history of IHD (83\%) 4.Past history of CVA (60\%) 5. COPD (34\%) 6.Dyslipidemia (54.3\%) 6.Hypothyroidism (25.7\%). Cardiac troponin $\mathrm{T}$ trails group study showed increased risk of myocardial injury in patients with history of diabetes and old IHD $(p=0.002)$ which was consistent with the results of our study ${ }^{8}$. It was observed that the mean TSH value in the present study in patients with hypothyroidism who had myocardial injury was $0.94 \mathrm{IU} / \mathrm{ml}$ and who did not develop myocardial injury was $3.46 \mathrm{IU} / \mathrm{ml}$ which was statistically significant $(\mathrm{p}=0.002)$.In our study incidence of myocardial injury and all cause mortality was found to co- relate with: (1) Use of vasopressor agents for maintaining adequate tissue perfusion $(\mathrm{p}=0.04)$, which was consistent with a study done by liu et $\mathrm{al}(\mathrm{p}=0.03)^{9}$.(2) Anemia (significant in patients with moderate and severe anemia) with $\mathrm{p}=0.001$, similar to a study done by fabio et al. $(\mathrm{p}=0.002)^{10}$. (3) Hypoxia: Mean po2 values were between $45-55 \mathrm{mmHg}$ in patients who 
had myocardial injury and death in our study $(\mathrm{p}=0.001)$ which was consistent with a study done by fabio et al. $(p=0.003)^{10}$.(4) The blood sugar level at the onset of symptoms when patients had myocardial injury ranged between 90 and 460mg/dl, signifying both hypoglycemia and hyperglycemia were risk factors for myocardial injury in the present $\operatorname{study}(\mathrm{p}=0.002)$. Similar results were seen in a study done by subramanyan et al. $(p=0.001)^{11}$. In the present study, HbA1C > 8.5 was associated with significant incidence of myocardial injury and death $(\mathrm{p}<0.001)$, which was consistent with a study done by mahmut et $\mathrm{al}(\mathrm{p}=0.004)^{12}$. In the present study there was no significant correlation between serum sodium and potassium levels in patients who had myocardial injury ( $\mathrm{p}=0.218$ and $\mathrm{p}=0.318$ ) respectively. The results are consistent with study done by Micheal Liu et $\mathrm{al}(\mathrm{p}=0.080)$ and verma et $\mathrm{al}(\mathrm{p}=0.41)^{9}$, But there was significant co-relation between hyponatremia and hypokalemia in relation to myocardial injury $(\mathrm{p}=0.02)$, in a study done by wali $\mathrm{M}$ et $\mathrm{al}^{13}$.

\section{Conclusion}

The common comorbidities found in the study are Diabetes Mellitus, Hypertension, Obstructive airway disease, Hypothyroidism in various combinations. The parameters related to these comorbidities are poorly controlled in patients who had myocardial injury

The factors mentioned below could be precipitants in an acutely sick elderly.

1) Hypoxemia(76\%) $\mathrm{p}=0.003$

2) Hypotension with use of vasopressor agents $(68.5 \%) \mathrm{p}=0.040$

3) Hypoglycemia $(44.5 \%)$ and

Hyperglycemia $(66 \%) \mathrm{p}=0.001$

4) anemia $p=0.001$

5) Poorly supplemented hypothyroidism $(25.7 \%) \mathrm{p}=0.03$

The above trigger factors fortunately are easily treatable and preventable factors. Hence all elderly patients with or without multiple comorbidities who are hospitalised with acute form of stressors must be aggressively evaluated for precipitants and adequately treated.

The same guidelines can be extrapolated to elderly patients followed up as outpatient. Elderly patients on opd follow up required to be examined and assessed for the above trigger factors to prevent the additional risk.

\section{Bibliography}

1. Kadaklouche et al, The Diagnostic Challenge of Myocardial Infarction in Critically Ill Patients: Do High-sensitivity Troponin Measurements Add More Clarity or More Confusion? Critical Care 2014 18:148.

2. Ian webb and jamescoutts, Myocardial Infarction on the ICU: can we do better? Critical Ccare 2008,12:129.

3. Priyanka G, Myocardial injury in critically ill elderly patients with non-cardiac diagnosis at admission,2016.

4. Berlot G, Vergolini A, Calderan C, Bussani R, Torelli L, Lucangelo U. Acute myocardial infarction in non-cardiac critically ill patients: a clinicalpathological study. Monaldi Archives for Chest Disease. 2010;74(4).

5. Wendy Lim et al, Elevated Cardiac Troponin Levels in Critically Ill Patients: Prevalence, Incidence, and Outcomes. American Journal of Critical Care, May 2006, Volume 15, No. 3.

6. Venkatesh, et al.: Atypical Manifestations of Diseases in Elderly Patients in Critical Care Areas. International Journal of Scientific Study | October 2015 | Vol 3 | Issue 7

7. Ostermann et al.: A prospective study of the impact of serial troponin measurements on the diagnosis of myocardial infarction and hospital and six-month mortality in patients admitted to ICU with non-cardiac diagnoses. Critical Care 2014 18:R62.

8. Cardiac Troponin T Trials Group., Elevated troponin and myocardial 
infarction in the intensive care unit: a prospective study. Critical Care 2005, 9:R636-R644.

9. Michael liu et al., Prognostic value of initial elevation of cardiac troponin I level in critically ill patients without acute coronary syndrome. Critical Care Nurse 2015 Vol 35, No. 2.

10. Fabio et al. Anemia and Ischemia: Myocardial Injury in Elderly with Gastrointestinal Bleeding. American journal of Medicine 2005.118, 548-551.

11. Subramanian et al., Hypoglycemia and Myocardial Infarction: Inhibition of Ischemic Preconditioning Response. Indian journal of Endocrinology on Metabolism 2012 may-june, 16(3):473474.

12. Mahmut et al., The value of Admission Glycosylated Hemoglobin Level in patients with Acute Myocardial Infarction. Canadian Journal of Cardiology 2008 vol 24 no 5.

13. Wali $\mathrm{M}$ et al., Prognostic Importance of Hyponatremia in ST Elevation Myocardial Infarction. American Journal of Medicine 2004, 117, 242-248. 